\title{
HISTÓRIA, INSTITUIÇÕES ESCOLARES E O MATERIALISMO HISTÓRICO DIALÉTICO
}

\begin{abstract}
Rodrigo Sarruge Molina ${ }^{1}$
\section{Resumo}

Esse artigo objetiva analisar a contribuição teórico-metodológica do materialismo histórico dialético para o campo da Educação, especialmente para o estudo histórico das Instituições Escolares. Resultado de debates desenvolvidos na pós-graduação da Faculdade de Educação da UNICAMP constatamos a grande importância dos estudos das instituições escolares para a área da educação, pois enriquecem a prática pedagógica nas escolas, fortalecem os compromissos desses autores institucionais com a educação e desenvolve o conjunto da área da Educação, pois a história das escolas é a própria História da Educação. Nesse sentido, concluímos que o materialismo histórico dialético tem fundamental contribuição para a Educação, dado que sem o auxílio desse campo teórico e metodológico os estudos da história das instituições escolares ficariam, ainda mais, sem problemas e objetos.
\end{abstract}

Palavras-chave: Materialismo histórico dialético. Instituições escolares. Marxismo. História da educação. Gramsci.

\section{HISTORY, SCHOOL INSTITUTIONS AND DIALECTICAL HISTORICAL MATERIALISM}

\begin{abstract}
This article aims to analyze the theoretical-methodological contribution of dialectical historical materialism to the field of Education, especially for the historical study of School Institutions. As a result of the debates developed at the Faculty of Education of UNICAMP we note the great importance of studies of school institutions in the area of education, as they enrich pedagogical practice in schools, strengthen the commitment of these institutional authors to education and develops the whole area of Education, since the history of schools is the History of Education itself. In this sense, we conclude that dialectical historical materialism has a fundamental contribution to education, given that without the aid of this theoretical and methodological field, the studies of the history of school institutions would remain, without problems and objects.
\end{abstract}

Keywords: Dialectical historical materialism. School institutions. Marxism. History of education. Gramsci. 


\title{
HISTORIA, INSTITUCIONES ESCOLARES Y EL MATERIALISMO HISTÓRICO DIALÉTICO
}

\begin{abstract}
Resumen
Este artículo objetiva analizar la contribución teórico-metodológica del materialismo histórico dialéctico para el campo de la Educación, especialmente para el estudio histórico de las Instituciones Escolares. Los resultados de los debates desarrollados en el postgrado de la Facultad de Educación de la UNICAMP constatamos la gran importancia de los estudios de las instituciones escolares para el área de la educación, pues enriquecen la práctica pedagógica en las escuelas, fortalecen los compromisos de esos autores institucionales con la educación y la educación desarrolla el conjunto del área de la Educación, pues la historia de las escuelas es la propia Historia de la Educación. En ese sentido, concluimos que el materialismo histórico dialéctico tiene fundamental contribución a la Educación, dado que sin el auxilio de ese campo teórico y metodológico los estudios de la historia de las instituciones escolares quedarían aún más, sin problemas y objetos.
\end{abstract}

Palabras clave: Materialismo histórico dialéctico. Instituciones escolares. Marxismo. Historia de la educación. Gramsci.

\section{INTRODUÇÃO}

Esse artigo $^{2}$ objetiva realizar uma breve reflexão acerca da contribuição da teoria e método materialista histórico dialético para estudo histórico das instituições escolares, campo de trabalho de muitos pesquisadores da atualidade. No primeiro tópico realizamos um debate sobre as questões historiográficas abordadas pela tradição marxista e algumas problemáticas da atualidade, onde o irracionalismo ganha força na sociedade e academia. O segundo tópico objetivou discutir a questão das fontes históricas trabalhadas pelos pesquisadores da História da Educação por meio do questionamento metodológico de alguns historiadores. No terceiro tópico, após acumular conteúdo teórico nos interrogamos: "Qual a importância de estudar as instituições escolares?", quando analisamos a grande importância desse estudo para a área da Educação e da História. O quarto e último tópico é destinado a focalizar as relações entre o campo da história das instituições escolares e a questões teórico-metodológica do materialismo histórico dialético, quando concluímos que sem a teoria, o conhecimento não avança.

\section{CONSIDERAÇÕES HISTORIOGRÁFICAS}

Partimos do princípio que realizar estudos sobre as instituições escolares por meio do materialismo histórico dialético não deve ser um exercício de mostrar a face visível dos acontecimentos, isto é, reiterar a História oficial, as memórias e folclores das instituições 
Artigo

doi: $10.20396 /$ rho.v18i4.8652660

estudadas, mas por tratar-se de um estudo científico de História, deve-se trabalhar no sentido de "[...] revelar os aspectos essenciais das relações sociais que se ocultam sob fenômenos que se mostram à nossa percepção imediata" (SAVIANI, 2011, p. 201), ou melhor, é uma análise que procura publicar os aspectos não visíveis do cotidiano, "[...] revelar a face invisível da lua.” (SAVIANI, 2011, p. 201).

Portanto, os estudos das instituições escolares que pretendem utilizar o materialismo histórico dialético não são compatíveis com as perspectivas históricas tradicionalistas, como o presentismo e o positivismo (SCHAFF, 1987), memorialismo, irracionalismo, pós-modernismo e das "histórias" feitas para vender que, por serem interessadas em agradar seus leitores, realizam escritos místicos e fantasiosos da realidade, objetivando fomentar a indústria do entretenimento, como se consumir "história" fosse a mesma coisa que consumir revistas sensacionalistas, um grande nicho mercadológico que também operam como verdadeiros partidos políticos. (DOSSE, 2003).

Para além de um mercado lucrativo, é importante alertar que a "história" fabricada não é neutra, como alguns de seus empresários e dirigentes advogam. Pelo contrário, cada dia que se passa fica claro que essas "histórias" também tem uso político-eleitoral em regimes supostamente "democráticos" ou são usadas para a manutenção de ditaduras.

Geralmente, estas manipulações restabelecem ou recriam um passado que não possui relevância com o momento presente e por isso são forjadas, restauradas ou ressuscitadas por meio de um passado real ou imaginário, como foi, por exemplo, “[...] a pretensão sionista de retornar à pré-diáspora passada na terra de Israel que era, na prática, a negação da história real do povo judeu por mais de 2 mil anos" (HOBSBAWM, 1999, p. 28) ou os diferentes mitos fundadores do Brasil, uma das sociedades mais violentas do planeta que é propagandeada como fraterna, cordial e pacífica, pois seriamos abençoados por Deus e contemplados com uma democracia racial, onde não existiriam problemas com o racismo, mesmo que o genocídio de índios e negros ainda esteja ocorrendo, passados mais de 500 anos de invasão europeia ${ }^{3}$. (CHAUÍ, 2000).

Portanto, a História, enquanto campo das ciências humanas não é neutra. No ofício do historiador, os textos e ideias são em última instância ideológicos ou políticos. Nesse sentido, o compromisso do materialismo histórico dialético deve ser com a "verdade revolucionária" e por isso, são trabalhos que não estão interessados em agradar "seletos" clientes ou "possíveis" eleitores. O objetivo desse campo histórico é utilizar a ciência da História para auxiliar na interpretação da realidade e na transformação dessa sociedade imersa na barbárie. Como disseram Karl Marx e Friedrich Engels: “[...] os filósofos se limitaram a interpretar o mundo de diferentes maneiras; mas o que importa é transformálo." (MARX; ENGLES, 1987, p. 128).

Explicando melhor, apesar de a História não ter poderes "sobrenaturais" de antever o futuro, pode ser uma grande ferramenta para a compressão da realidade e projetar o 
Artigo

doi: $10.20396 /$ rho.v18i4.8652660

futuro por meio da compreensão de padrões e dinâmicas de transformação material da história e sociedade.

Nas palavras de Antonio Gramsci, compreende-se que "dizer a verdade é revolucionário", dominantes forjam das classes oprimidas e exploradas para manter-se no controle da sociedade poderá auxiliar na transformação da realidade, portanto, a verdade é palpável, ela é real e é um combustível para a mudança.

Historicizando a ideia, podemos melhor compreendê-la: o que os intelectuais da burguesia francesa revelavam no período revolucionário (1789-1799) foi fundamental para a derrubada da monarquia absolutista, assim como os ensinamentos de Lenin na Revolução Russa em 1917 auxiliaram as forças revolucionárias na derrubada da monarquia Czarista. À cada época, são os interesses da classe revolucionária que representa o máximo de consciência possível; " [...] este privilégio, que era no passado da burguesia revolucionária (filosofia do iluminismo, economia política clássica e outras) pertence agora à classe revolucionária de nossa época: o proletariado." (LOWY, 1987, p. 197).

Isso ocorre, pois após a Revolução Francesa até a contemporaneidade, o proletariado é a classe universal que coincide com os interesses da maioria da humanidade. Seus interesses internacionalistas caminham no sentido de abolição de toda a dominação que é submetida pelo capitalismo multinacional, grosso modo, são $99 \%$ de explorados contra 1\% de beneficiados (HALIMI, 2017), o que não obriga o proletariado a esconder os conteúdos de dominação de classes, ao contrário, o desvendamento do conteúdo histórico dessa exploração é fundamental para as futuras lutas de libertação.

De acordo com Michael Löwy, “[...] o conhecimento objetivo da realidade, da estrutura econômica e social, da relação de forças e da conjuntura política é, portanto, uma condição necessária de sua prática revolucionária" (LOWY, 1987, p. 199-200), ou seja, a racionalidade científica e a proximidade da verdade é a arma do combate do proletariado, bases sem "a qual ele não pode prosseguir. (LOWY, 1987, p. 199-200).

Tudo isso não significa que, produzir ciência do ponto de vista dos interesses dos explorados é estar preso a "guetos" e dogmatismos ou como fazem alguns intelectuais, que presos a "camisas de forças" limitam-se ao estudo apenas de obras comprometidas com a revolução ou credenciadas pelo partido " $\mathrm{x}$ ". Melhor explicando, o desenvolvimento científico é fruto de conquistas e descobertas adquiridas no decorrer de toda a história da humanidade. Muitas contribuições greco-romanas, indígenas, da igreja, da nobreza ou da burguesa são fundamentais e devem ser compreendidas, absorvidas e superadas. Segundo Löwy:

[...] a história da ciência social desenvolve com um certo nível de continuidade: Marx continua-critica-supera Ricardo, e o mesmo tipo de relação dialética (Aufhebung) define a ligação entre Lukács e Max Weber. Apresentar (como faz o marxismo positivista) o marxismo como ciência da sociedade (ou da história) 
simplesmente, face à qual as outras teorias não seriam senão `ideologias’, é uma pretensão arrogante que (como vimos) Marx não partilha absolutamente e que torna incompreensível o tipo de relação que existe entre elas depois de um século de cientistas marxistas e não-marxista. (LOWY, 1987, p. 203).

Portanto, a ciência produzida do ponto de vista dos interesses do proletariado deve ser vasta e totalizante, isto é, deve integrar em seu "campo" as diversas verdades parciais produzidas pelas ciências de outros contextos históricos e de outras classes sociais, mesmo que tenham contribuições limitadas para a construção da revolução. Exemplificando: ao integrar em sua análise certas críticas de Sismondi ao capitalismo, Marx e Rosa Luxemburgo não se tornaram mais ecléticos, e não encobriram as divergências fundamentais que os separavam deste economista que sonhava com um retorno ao passado. (LOWY, 1987, p. 207-208).

Assim, compreendemos que é fundamental não estarmos fechados em "guetos" ou "dogmatismos" e abrir-se para a incorporação e a superação de análises e contribuições de outras escolas históricas, como é por exemplo a "Escola dos Annales" (BURKE, 1997) e acrescentar a esse debate o materialismo histórico-dialético tal como Marx e Engels pensaram.

Acreditamos que esses procedimentos teóricos e metodológicos poderão auxilia-nos na construção de uma sociedade mais democrática no sentido de combater as desigualdades sociais que fazem o Brasil ser um dos países mais violentos do mundo.

Do ponto de vista da produção da História, isso não significa que devemos "aprisionar" nossas fontes, ou seja, "forçar" nossas fontes a "falarem" de acordo com nossos desejos utópicos e interesses políticos, “[...] o trabalho do historiador de descobrir de onde viemos e para onde estamos indo não deve ser afetado enquanto trabalho pelo fato de gostarmos ou não dos resultados prospectivos." (HOBSBAWM, 1999, p. 66).

Esse alerta aos historiadores tem sua materialidade. Historicamente, a burguesia enquanto classe revolucionária, produziu o desenvolvimento científico objetivo da economia dos clássicos dos fins do século XVIII e início do século XIX. A partir do momento em que a burguesia se transformou em classe dominante, sobretudo a partir de 1830, concomitantemente que se deparou com surgimento de uma nova classe expressa em um movimento operário organizado que ameaçava os interesses particulares baseados na propriedade privada, ela não pôde mais se dar ao luxo desse desinteresse, dessa objetividade científica, necessitou, após conquistar o poder de uma apologética, de uma legitimação pura e simples de seus interesses, de uma ideologia a serviço de sua posição de classe. "Nesse momento, declina, e morre, a economia política científica e é substituída pela economia política vulgar", uma ideologia que, caso necessário, manipula a verdade objetiva para a manutenção do status quo da classe burguesa ${ }^{5}$. (LOWY, 1998, p. 98-99).

Nas palavras de Karl Marx em 1873: 


\begin{abstract}
A burguesia, em França e Inglaterra, tinha conquistado o poder político. Daí em diante a luta de classes ganhou, praticamente e teoricamente, formas mais e mais declaradas e ameaçadoras. Dobrou a finados pela Economia burguesa científica. Não mais se tratava agora [de saber] se este ou aquele teorema era verdadeiro, mas de se era útil ou prejudicial ao capital, cómodo ou incómodo, de se era ilegal ou não. Para o lugar da pesquisa desinteressada passou o pugilato profissional pago, para o lugar da investigação científica imparcial a má consciência e a má intenção da apologética. (MARX, 2007, s/p).
\end{abstract}

No entanto, é delicado falar sobre a verdade e a manipulação do conhecimento na contemporaneidade, especialmente por conta da hegemonia cultural pósmoderna/irracionalista na maior parte da sociedade. No Brasil, especialmente na década de 1990, do ponto de vista da teoria histórica, ocorreu um grande avanço de abordagens não comprometidas com a compreensão da sociedade, por meio de um pluralismo epistemológico e temático, análises mais concretas, sociais e que visam a compreender a totalidade foram abandonadas para a adoção de abordagens mais subjetivas e pessoais, os objetos agora eram singulares. Esse fenômeno foi conhecido como "crise dos paradigmas" e teve seus pontos positivos e negativos. O positivo foi representado "[...] pela ampliação das linhas de investigação, diversidade teórico-metodológica e utilização das mais variadas fontes de pesquisa." (BUFFA; NOSELLA, 2009, p. 16-17). Já os pontos negativos foram as fragmentações epistemológicas e temáticas que tem dificultado a compreensão da totalidade" dos fenômenos históricos e educacionais sendo que muitos negam a possibilidade de existência da verdade, pois tudo é subjetivo, fragmentado e portanto, irracional. (BUFFA; NOSELLA, 2009, 16-17).

Para os autores pós-modernos "existe": a recusa da análise dos "processos históricos" e seus determinantes gerais; negação do trabalho com as metanarrativas e defesa da compreensão do singular e subjetivo dissociado do universal, ou seja, do conjunto de relações sociais historicamente determinadas; interpretação de um mundo irracionalmente compreendido, isto é, uma realidade não material, "impalpável”, impossibilitada de ser transformada e por fim, rejeição de analises marxistas, “[...] como intervenção consciente dos homens sobre o processo histórico, como indivíduos dispostos em classes sociais e não autodeterminados." (MINTO, 2014, p. 13).

Esse fenômeno novidadeiro baseado na irracionalidade não é restrito somente ao campo da história, mas abrange o conjunto das ciências humanas, desde a psicanalise até a antropologia ou qualquer "[...] outra disciplina que possa ajudar credenciar os jovens a uma reputação pelo lançamento de uma nova moda ou pela formação de algo que ninguém disse antes." (HOBSBAWM, 1999, p. 78).

Ter a novidade como etiqueta ajuda a vender a história entre os profissionais, tal como ajuda a vender detergentes entre um público mais amplo. Naturalmente minha objeção não é quanto aos historiadores tomarem de empréstimo técnicas e ideias de outras ciências sociais e incorporarem a seu próprio trabalho os mais recentes desenvolvimentos nessas ciências, desde que sejam úteis e pertinentes. 
É quanto à distribuição da bagagem histórica em uma série de vasos não comunicantes. Não existe uma coisa do tipo história econômica, social, antropológica ou história psicanalítica: existe apenas história. (HOBSBAWM, 1999, p. 78).

Apesar de respeitar a opção de os sujeitos pós-modernos não acreditarem na possibilidade de criar conhecimento científico, pois em suas acepções, não existe a verdade, somos adeptos da opção contrária. Acreditamos que sim, é possível encontrar a verdade na produção do conhecimento científico. De acordo com o historiador britânico Eric Hobsbawm (1999), defendemos vigorosamente a opinião de que nossas investigações são reais, baseadas em declarações sujeitas a evidenciação, distinguindo o comprovável da ficção. É fato que ocorreu a escravidão no Brasil colônia e império, foram os bandeirantes que aprisionaram os índios, e não o contrário. "O modo como montamos e interpretamos nossa amostra escolhida de dados verificáveis (que pode incluir não só o que aconteceu, mas o que as pessoas pensaram a respeito) é outra questão.” (HOBSBAWM, 1999, p. 8).

Continuando com as contribuições do historiador inglês, devemos alertar para os perigos dos fanatismos no campo da História. Muitos historiadores ou aspirantes realizam manobras irresponsáveis de manipulação de textos pretensamente históricos com objetivos comerciais e políticos, atitudes irresponsáveis que produzem perigosas armas incendiárias que podem fomentar uma série de intolerâncias.

Historicamente, os indivíduos e grupos de indivíduos sempre procuraram alguém a quem atribuir a culpa por seus fracassos, inseguranças, dúvidas, angustias e frustrações. Por exemplo, no período de ascensão do nazismo na Alemanha, o problema da crise econômica e social era atribuída aos judeus, homossexuais, comunistas, ciganos, o que justificou uma série de produções acadêmicas e jornalísticas que legitimavam a famosa política de extermínio, eternizada com o holocausto.

\footnotetext{
A história é a matéria-prima para as ideologias nacionalistas ou étnicas ou fundamentalistas, tal como as papoulas são a matéria-prima para o vício da heroína. Se não há nenhum passado satisfatório, sempre é possível inventá-lo. De fato, na natureza das coisas não costumam haver nenhum passado completamente satisfatório, porque o fenômeno que essas ideologias pretendem justificar não é antigo ou eterno mas historicamente novo (...)Nessa situação os historiadores se veem no inesperado papel de atores políticos. Eu costumava pensar que a profissão de historiador, ao contrário, digamos, da de físico nuclear, não pudesse, pelo menos, produzir danos. Agora sei que pode. Nossos estudos podem se converter em fábricas de bombas, como os seminários nos quais o IRA aprendeu transformar fertilizante químico em explosivos. Essa situação nos afeta de dois modos. Temos uma responsabilidade pelos fatos históricos em geral e pela crítica do abuso político-ideológico da história em particular. (HOBSBAWM, 1999, p. 17-18).
}

Essas questões são realmente delicadas, pois podem determinar o conteúdo dos livros escolares, das reportagens jornalísticas ou os programas de televisão e, até mesmo, as supostas teses científico-acadêmicas, como as que justificaram a pobreza da África e 
Artigo

doi: $10.20396 /$ rho.v18i4.8652660

América Latina por nossas origens genéticas, teses conhecidas do "darwinismo social" que legitimaram ideologicamente muitas invasões imperialistas.

Portanto, devemos estar atentos, pois o trabalho de um historiador deve estar atrelado à constante lembrança de nossas responsabilidades, ou seja, um continuo esforço de nos isentar de nossas paixões, mesmo se a sentimos, pois no fim das contas, somos seres de "carne e osso". "Infelizmente uma coisa que a experiência histórica também ensinou aos historiadores é que ninguém jamais parece aprender com ela. No entanto, temos que continuar tentando." (HOBSBAWM, 1999, p. 27).

\section{SOBRE AS FONTES HISTÓRICAS}

A questão da escolha das fontes para a pesquisa é sempre controversa, muitos pesquisadores visam a pesquisar apenas uma matriz, como são os jornais, outros, apenas as fotografias. No entanto, alertamos o leitor que nem todos os documentos históricos encontrados e utilizados nas pesquisas são fiéis retratos da história, ou seja, os documentos históricos no momento em que foram produzidos também refletiam as ambições, desejos e políticas da época, muitas vezes forjados para defender determinados interesses particulares de indivíduos ou coletivos de classe.

As fontes primárias documentais impressas são realmente "sedutoras" e muitas vezes de difícil acesso, seja pela organização dos arquivos ou mesmo por obedecerem uma lógica privatista das informações. Porém, esses documentos não bastam para a produção científica da História. É preciso confrontá-las com outras informações, desde as fontes orais, que viveram esses períodos históricos, até bibliografias que já examinaram o período histórico em questão. Por exemplo, apesar da riqueza de informações dos jornais do período da ditadura (1964-1985), esses materiais não garantem a veracidade dos acontecimentos da época, pois a maior parte das empresas jornalísticas foi simpática à ditadura, inclusive patrocinando o regime com veículos automotores.

O caso emblemático foi a revelação que a Comissão Nacional da Verdade fez em 2014, afirmando que o jornal "Folha de São Paulo" deu apoio financeiro e ideológico ao regime, especialmente para a Operação Bandeirante (OBAN). A confiança nas informações da imprensa brasileira diminui ainda mais quando sabemos que as redações eram submetidas à vigilância de censores e de patrões que constrangiam qualquer tentativa dos jornalistas de usarem o utópico recurso da "liberdade de expressão". (KUSHNIR, $2014)^{7}$.

Os jornais sob censura davam raras notícias, quase sempre truncadas, falseadas, fornecidas diretamente pelos órgãos de segurança, interessados em atribuir, a tiroteio nas ruas, a morte de militantes e simpatizantes nas salas de tortura. Apesar de estar nu, o rei decretava que todos apreciassem suas vestes. Alguns jornalistas atenuavam sua cumplicidade com a mentira oficial publicando, nos espaços censurados, receitas de bolo ou poemas de Camões. Os acólitos do 
regime adaptavam-se, substituíam o noticiário cortado, antecipavam-se à tesoura do censor, exercendo, sem escrúpulos, um aprendizado que faria escola no jornalismo brasileiro: a autocensura. A insólita lição ensinava que o bom profissional deve alienar-se de suas ideias e convicções para escrever como o patrão escreveria e editar como o governo editaria. Não era apenas a força de trabalho alugada sob o imperativo da sobrevivência, como a prostituta que se oferece na esquina. Era a própria consciência adulterada, associando autoridade e verdade, como o torturador de dentes cariados e salário mínimo afoga a sua vítima numa banheira, em defesa de uma liberdade que ele não usufrui. (BETTO, 2006, p. 130).

Essa distorção da informação não é limitada aos jornais, como historiadores também devemos estar atentos às manipulações de outras fontes, como são os documentos oficiais. Muitos são forjados em processos de corrupção que omitem a veracidade dos fatos, como por exemplo, mentiras criadas para mascarar mortes resultantes de torturas dentro de repartições estatais, como o DEOPS ou aparelhos militares das forças armadas. Caso clássico é o do jornalista Vladmir Herzog, torturado e assassinado dentro das instalações do DOI/CODI/II Exército em São Paulo e que foi diagnosticado pelos documentos oficiais de morte em decorrência de suicídio. ${ }^{8}$

Em todo caso, acreditamos que a análise crítica destas notícias da imprensa e outras fontes primárias, confrontadas com outras fontes e bibliografias, concomitante a uma grande a atenção aos procedimentos teóricos-metodológicos podem gerar resultados positivos. Apesar de muitos materiais oficiais serem "distorcidos" e censurados por motivações políticas ou pressões psicológicas, enquanto documento histórico são importantes relatos da memória da época. (LE GOFF, 1990).

De acordo com Buffa e Nosella (2009, p. 58), a leitura das fontes históricas não é tarefa fácil e depende da ótica teórica, ética e política do pesquisador. Diante disso, os professores recomendam que os historiadores devam construir, demolir e reconstruir suas fontes, ou seja, a análise, a reflexão e a síntese dos acontecimentos passados não significam de maneira alguma a transcrição integral das fontes existentes como verdade suprema, pois, como afirmamos anteriormente, estas são forjadas por homens e portanto, sujeitas a influências políticas, econômicas, ideológicas e culturais de um determinado contexto histórico. Investigar e representar a História não é simplesmente descobrir coisas que supostamente ocorreram no passado, mas relacionar esses fatos com a sociedade do contexto estudado. Para exemplificar, descobrir que no crepúsculo vespertino do dia 22 de abril de 1500, Pedro Alvares Cabral e sua frota avistaram o litoral brasileiro não significa a compreensão da temporalidade do período das grandes navegações e a colonização do Brasil.

Com relação ao estudo das instituições escolares, esses procedimentos críticos devem ser adotados para o conjunto de fontes coletadas no decorrer da pesquisa, sejam as fotografias da primeira turma de alunos formados na escola, os documentos oficiais 
assinados pelo diretor da escola que visou fechar salas de aulas ou as entrevistas realizadas na contemporaneidade com os ex-alunos.

Portanto, o desafio dos historiadores será se afastar das tendências positivistas que acreditam que a verdade se encontra nos documentos e que o papel do historiador é passivo, receptivo e neutro. Não acreditamos que exista uma harmonia natural na sociedade, assim como ocorre na biologia, ao contrário, acreditamos que as diferentes sociedades são historicamente determinadas em seus diferentes períodos por modos diversos de sobrevivência material e cultural. ${ }^{9}$

Assim como os documentos manuscritos e as notícias da imprensa, o trabalho com a história oral, por meio de entrevistas gravadas, também está sujeita às distorções da memória humana, muitas vezes reais ou fantasiosas e, portanto, também não podem ser encaradas como relatos fiéis da História, assim como as fotografias que muitas vezes são encenações "teatrais" realizadas pelos personagens e o fotógrafo.

\begin{abstract}
Em outras palavras, o pesquisador estuda e reconstrói o passado numa perspectiva cultural de valores atuais e assim avalia pessoas e instituições. Ele elabora uma síntese original entre o nível êmico e o nível ético, isto é, mesmo distinguindo o que pensavam e faziam as pessoas hoje, o pesquisador não pode deixar de realizar uma integração entre os dois níveis, por isso, o pesquisador de uma instituição, na verdade, cria uma realidade totalmente original, quase uma "ficção", melhor dizendo, cria uma obra de arte, rica de sentidos. Essa obra, porém, não é uma construção arbitrária, menos ainda uma mentira, pois tem fontes como base, tampouco é uma reprodução mecânica de algo que está fora dele. É uma obra de cultura enraizada, de um lado, em fontes e valores do passado e, de outro, em valores do presente, em defesa de um projeto social. (BUFFA; NOSELLA, 2009, p. 71-72).
\end{abstract}

\title{
INSTITUIÇÕES ESCOLARES, PORQUE ESTUDAR?
}

Partimos do princípio que pesquisar as instituições escolares e publicar trabalhos de História dessas instituições é um instrumento "para uma nova compreensão da história da escola", elevando o conhecimento de sua comunidade acadêmica, sejam funcionários, professores e alunos e a população envolvida com esse espaço público ou privado. Constatamos que a partir do momento em que se eleva o conhecimento desses "atores" institucionais de forma crítica, aumenta-se a responsabilidade dos mesmos em suas ações, envolvimento e comprometimento com a vida institucional, dinâmica que pode colaborar para a evolução da entidade educacional. Nesse sentido, não se tratam de trabalhos que se propõem a impor "lições de moral" sobre o que ocorreu ou deveria ter ocorrido, ao contrário, os estudos de História das instituições escolares colaboram para o avanço do conhecimento, ampliando nossos horizontes, perspectivas e auxiliando-nos a rever nosso passado criticamente e escolher novos caminhos para o presente e futuro. 
Segundo (BUFFA; NOSELLA, 2009, p. 32-39), os estudos das instituições escolares também podem colaborar para aumentar positivamente os aspectos emocionaisafetivos da comunidade com a escola estudada, aumentando assim o sentimento de orgulho e autoestima de se pertencer àquela instituição cuja a história agora é reconhecida.

Para além da elevação "moral” e comprometimento com a vida institucional, essa história, quando publicada, pode auxiliar seus leitores e atores, na elevação de seus aspectos cognitivos e políticos, pois ao tomarem conhecimento dos aspectos da história de sua instituição escolar, podem se instrumentalizar e tomar condutas de acordo com o passado. Saber, por exemplo, que o partido " $x$ " do prefeito " $y$ " fechou salas de aula, prejudicando o ensino na escola, pode ser útil para não fazer alianças políticas com esses sujeitos. Em suma, a História pode auxiliar alunos, professores e funcionários no clareamento de algumas práticas políticas da instituição para a defesa de seus interesses.

A prática pedagógica também é enriquecida com esses estudos históricos, porque os professores podem se auxiliar dessas informações históricas para aprimorar sua prática docente contemporânea. Para ilustrar, peguemos um estudo sobre instituições escolares, onde o auto estudou o campus "Luiz de Queiroz" da Universidade de São Paulo. (MOLINA, 2016). Saber, por exemplo, que nas origens dessa escola, em 1901, o ensino era intercalado entre lições teóricas nas salas de aula e laboratórios e lições práticas nos campos de experimento nas fazendas e indústrias pode enriquecer as relações entre teoria e prática em 2017, fundamentais para a formação de um agrônomo omnilateral, ou seja, um homem formado em sua totalidade por meio de sua convivência em sociedade e de seu trabalho.

Esses estudos históricos também são fatores fundamentais para a preservação de patrimônios históricos e culturais da humanidade, pois a publicação de arquivos, fontes e arquiteturas institucionais nesses estudos são uma maneira de proteger e incentivar a ida de novos pesquisadores a esses locais, colaborando para sua proteção. Infelizmente, no Brasil, são inúmeros os arquivos e prédios que são destruídos pela falta de conhecimento geral sobre a importância da proteção da memória para a produção da história, fundamental para a identidade, cultura, soberania e desenvolvimento da nação e da humanidade. O incêndio do Museu Nacional no Rio de Janeiro em 2018 é prova desse abandono dos bens públicos.

Outro fator fundamental sobre o estudo das instituições escolares é sua importância para os campos científicos da História e da Educação, ou seja, são estudos que não devem ser limitados somente ao registro do passado ou presente de uma escola por meio de fontes diversas, mas sim, a compreensão e interpretação "da própria educação praticada em uma dada sociedade e que se utiliza das instituições escolares como espaço privilegiado para executá-la", assim, por meio da história singular de uma escola podemos revelar como ocorreu o processo educativo escolar de uma sociedade. (ARAÚJO; GATTI JUNIOR, 2002). 
Portanto, precisamos ressaltar que o estudo da história das instituições escolares é fundamental para a compreensão da educação pois, as histórias das escolas é a própria história da educação, - “[...] e não uma mera subdivisão dela.” (SANFELICE et al., 2016, p. 28).

De igual importância são esses estudos para a comunidade extra-acadêmica. Quando o conjunto da sociedade percebe a importância da instituição, na leitura aberta e democrática de sua memória e história, potencializa-se a participação no espaço escolar de pais de alunos, ex-alunos, aposentados, frequentadores do campus, futuros estudantes, políticos, empresários, partidos, associações de bairros, ONGs e demais organizações. Essa participação pública desperta a atenção da sociedade e suas lideranças para as necessidades da escola, potencializando e agilizando a resolução de seus problemas. (BUFFA; NOSELLA, 2009).

No fim, apesar dos conhecimentos ampliados e a participação coletiva, o destino da intuição escolar dependerá da sabedoria e liberdade entre os diferentes atores desse espaço, sejam internos como externos, sabendo discernir em suas ações concretas diárias, a escolha pela paz, a igualdade, a liberdade e a fraternidade ou a barbárie, o individualismo, a indiferença, o egoísmo, a economia da guerra permanente, características fundantes do capitalismo do século XXI. (BUFFA; NOSELLA, 2009).

\section{INSTITUIÇÕES ESCOLARES: O MÉTODO DE INVESTIGAÇÃO MATERIALISTA HISTÓRICO E DIALÉTICO}

Após compreendermos a relevância do estudo das instituições escolares, a seguir, discorreremos sobre a importância do debate teórico e metodológico para o oficio do historiador. Sem esses estudos, a produção de trabalhos na área da História da educação ficaria “[...] restrita a uma mera descrição narrativa, e uma história sem objeto, sem problemas e sem indagações. Isso significa que sem a teoria, o conhecimento não avança [...]" prejudicando a importância da produção da síntese histórica, assim como da historiografia. (NORONHA, 2007, p. 167).

Do ponto de vista metodológico, de acordo com Magalhães (1998), o estudo das instituições escolares deve compreender e explicar os processos e os "compromissos" sociais da escola como condição instituinte, ou seja, a função institucional na regulação e de manutenção normativa da sociedade, analisando os comportamentos, representações e projetos de sujeitos e suas relações com a realidade material e sociocultural de contexto histórico estudado. (MAGALHÃES, 1998, p. 58).

Constatamos em nossos estudos de mestrado (MOLINA, 2011) e doutorado (MOLINA, 2016) que esses compromissos sociais são fundamentais para se entender a formação e a redefinição da classe dominante brasileira e suas relações com o 
Artigo

doi: $10.20396 /$ rho.v18i4.8652660

imperialismo, ou seja, estudar as relações desses setores da sociedade e suas relações com as instituições educacionais é fundamental para compreender os projetos educacionais que foram determinados para o conjunto da sociedade e também compreender de forma mais concisa a definição de "classe dominante", uma vez que o débil aprofundamento sobre essa categoria tem colaborado para banalizar a sua noção conceitual, tornando-a vazia e abstrata, "[...] uma vez que a carência de estudos do objeto em perspectiva histórica inviabiliza seu conhecimento crítico." (MENDONÇA, 2008).

É, pois, como dimensão da totalidade histórica que a historiografia das instituições escolares precisa ser escrita para superar as lacunas e as ausências de respostas que foram deixadas pela chamada "história tradicional" porque essas "ausências de respostas" têm sua origem na "ausência de perguntas" porque a realidade não responde nada espontaneamente. É preciso ter indagações e clareza teóricas e metodológicas do "lugar teórico" de onde está falando (do seu alcance e limites) para que seja possível fazer avançar a compreensão do objeto e dos modos de tratar-se o objeto nas relações que se estabelecem entre sujeito e objeto no processo de construção do conhecimento histórico. (NORONHA, 2007, p. 170)

Segundo esquema figurativo de Justino Pereira de Magalhães (MAGALHÃES, 2004 apud SAVIANI 2007, p. 25), a análise investigativa da história de uma instituição escolar deve ser enfocada a partir de 3 bases fundamentais: em primeiro lugar, devemos estudar a materialidade da escola (a escola instalada), o que já foi instituído, ou seja, "o suporte físico das práticas educativas", envolvendo a arquitetura e seus equipamentos como o material didático e sua estrutura organizacional; o segundo ponto fundamental é a descrição da representação da escola na sociedade, o que envolve "o sentido atribuído ao papel desempenhado" pela instituição. Aqui cabe analisar a tradição, as bibliografias, os projetos e planejamentos, os modelos pedagógicos, os estatutos, o currículo e os funcionários. "Seria (...) a materialidade-conteúdo enquanto antecipação ideal daquilo que deverá constituir a atividade própria da instituição." (MAGALHÃES, 2004 apud SAVIANI 2007, p. 25). O terceiro momento é o da apropriação, que "[...] corresponderia à materialidade-conteúdo em ato [...]", por exemplo, as incorporações do ideário pedagógico, [...] "[...] definindo-se a identidade dos sujeitos e da instituição e seus respectivos destinos de vida [...]" (MAGALHÃES, 2004 apud SAVIANI 2007, p. 25), isto é, seu público alvo. Ou seja, trata-se de formular a questão: a quem se destina a instituição que estou me propondo a reconstruir historicamente e que resultados ela pretendeu atingir com a ação empreendida? A busca de informações sobre o alunado será, portanto, um elemento importante na reconstrução histórica das instituições escolares, uma vez que, além de ajudar na definição do perfil institucional, trará, também, indicações importantes sobre sua relevância social. (MOLINA, 2011).

Mergulhar no interior de uma Instituição Escolar, com o olhar do historiador, é ir em busca das suas origens, do seu desenvolvimento no tempo, das alterações arquitetônicas pelas quais passou, e que não são gratuitas; é ir em busca da 
identidade dos sujeitos (professores, gestores, alunos, técnicos e outros) que a habitaram, das práticas pedagógicas que ali se realizaram, do mobiliário escolar que se transformou, e de muitas outras coisas. Mas o essencial é tentar responder à questão de fundo: o que esta instituição singular instituiu? O que ela instituiu para si, para seus sujeitos e para a sociedade na qual está inserida? Mais radicalmente ainda: qual é o sentido do que foi instituído? (SANFELICE et al., 2016, p. 28-29).

No sentido de responder estas indagações fundamentais, os trabalhos sobre as instituições escolares devem analisar as relações das escolas e seu entorno, ou melhor, as relações entre o local (escola) com o global (sociedade). Trata-se de um exercício em que deverão ser relacionadas as particularidades do objeto (micro) com o quadro geral das estruturas organizacionais da sociedade do recorte cronológico do estudo (macro). (SANFELICE, 2009, p. 198).

Logo, não é possível entender a história se os estudos ficarem limitados aos acontecimentos internos da escola, às memórias dos professores e alunos ou aos vestígios arqueológicos encontrados no edifício escolar, pois a maior parte das relações internas de uma instituição escolar é reflexo de questões de nível nacional com o Ministério da Educação e estadual e municipal com as Secretarias de Educação e até mesmo internacionais, como foi historicamente determinações de agências como o Fundo Monetário Internacional (FMI), o Banco Internacional de Desenvolvimento (BID) e a UNESCO da Organização das Nações Unidos que mediante a aceitação de seus receituários e cartilhas liberaram empréstimos para a área educacional. (MOLINA, 2011).

Por isso, os estudos da instituições escolares que são baseados no materialismo histórico dialético devem analisar as origens da instituição, os projetos pedagógicos, os regulamentos, a disposição arquitetônica, os funcionários, os diplomados, a(s) classe(s) social(ais) beneficiada(s), e os aspectos gerais da sociedade desse recorte histórico, como são, por exemplo, as relações dessa escola com os meio materiais de produção (economia), a política, a cultura, ou seja, em uma acepção marxista, os fatores da superestrutura. De acordo com Sanfelice (2006): [...] se produz um trabalho historiográfico das Instituições Escolares para interpretar o sentido daquilo que elas formaram, educaram, instruíram, criaram e fundaram, enfim, o sentido da sua identidade e da sua singularidade. No entanto, o trabalho maior do historiador, "[...] é compreender a relação do singular com o geral. (...), pois a instituição é objeto de interesses contraditórios de ordem econômica, política, ideológica, religiosa e cultural, dentre outros." (SANFELICE, 2006, p. 24-25).

Segundo escreveu Karl Marx, no prefácio da segunda edição de "O Capital”, para a realização de uma investigação que exponha o movimento real em sua totalidade, primeiramente devemos nos concentrar na análise dos aspectos particulares da matéria. Conforme afirmou no inverno londrino de 1873:

É mister, sem dúvida, distinguir, formalmente, o método de exposição do método de pesquisa. A investigação tem de apoderar-se da matéria, em seus pormenores, 
de analisar suas diferentes formas de desenvolvimento e de perquirir a conexão íntima que há entre elas. Só depois de concluído esse trabalho é que se pode descrever, adequadamente, o movimento real. Se isto se consegue, ficará espelhada, no plano ideal, a vida da realidade pesquisada, o que pode dar a impressão de uma construção a priori. (MARX, 2011, p. 28).

Desse modo, podemos afirmar que para compreendermos as singularidades de nosso objeto é fundamental analisarmos o universal, isto é, a totalidade histórica. O singular não existe sem o universal, da mesma forma que o universal não se institui sem as múltiplas e contraditórias relações singulares.

Essas relações dinâmicas entre o singular e o universal obedecem ao movimento:

[...] real da história, a paixão, a vontade humana, os conflitos, os dissensos, as relações de propriedade e de produção não fazem parte de um jogo abstrato, predefinido, bem comportado. São, ao contrário, ingredientes de uma dura luta social, arriscada, cujo resultado final não se conhece. Por isso, nessa perspectiva metodológica, a instituição escolar não é vista a priori como a eterna reprodutora dos desequilíbrios sociais, tampouco como a redentora de todos os males: dialeticamente, a escola é um importante espaço de luta social pela hegemonia econômico-política. A dialética vê a história movimentar-se num processo contínuo de lutas, onde a tese não 'brinca' de se compor com a antítese, mas quer eliminá-la. Do futuro pode-se prever muita luta... (BUFFA; NOSELLA, 2009, p. 81-82).

Seguindo esse raciocínio, podemos afirmar que dentro da instituição existem homens de "carne e osso" e, por isso, estudar uma escola não é somente constatar em que ano foram construídas as salas de aulas ou os laboratórios, mas relacionar esses espaços físicos aos homens e suas complexas relações sociais, historicamente determinadas em um determinando recorte cronológico.

[...]os aspectos sociais ou societais da essência do homem não podem ser separados dos outros aspectos de seu ser, exceto à custa da tautologia ou da extrema banalização. Não podem ser separados, mais que por um momento, dos modos pelos quais os homens obtêm seu sustento e seu ambiente material. Nem por um só momento podem ser separados de suas ideias, já que suas mútuas relações são expressas e formuladas em linguagem que implica conceitos no momento em que abrem a boca. E assim por diante. (HOBSBAWM, 1999, p. 87).

Logo, os procedimentos de investigação do materialismo histórico dialético partem da constatação da existência de indivíduos humanos reais e da organização destes na história e sociedade, “[...] sem qualquer especulação ou mistificação [...]" (MARX; ENGELS, 1987, p. 35), “[...] em uma atitude polêmica e crítica como superação da maneira de pensar precedente e do pensamento concreto existente.” (GRAMSCI, 1995, p. 18). 


\section{CONCLUSÃO}

De forma aproximativa e sintética, compreendemos a teoria e metodologia materialista histórica dialética no estudo das instituições escolares como a investigação da conexão íntima entre a forma pela qual a sociedade produz sua existência material e a instituição escolar que cria, nesse sentido, pesquisar as instituições escolares por meio do materialismo histórico dialético implica na revelação dos aspectos das relações sociais que são ocultados de nossa percepção imediata para a manutenção do poder da classe dominante.

A História e a Educação, enquanto campo das ciências humanas não são neutras, o que determina o compromisso do materialismo histórico dialético com a "verdade revolucionária", pois "[...] os filósofos se limitaram a interpretar o mundo de diferentes maneiras; mas o que importa é transformá-lo.” (MARX; ENGLES, 1987, p. 128).

Constatamos que a História e a Educação, podem ser ferramentas para a compressão da realidade humana, por meio da constatação de padrões e dinâmicas de transformação material da sociedade, o que poderá nos auxiliar na projetação de um futuro racional, sustentável, igualitário, seguro e diverso para toda a humanidade.

Esse exercício de trabalho científico e histórico, comprometido com a libertação da humanidade, implica a construção, demolição e reconstrução das fontes primárias e secundárias no sentido da produção consciente e racional da História da Educação em oposição as teorias pós-modernas que advogam um mundo irracional e sem verdades ou aquelas positivistas engessadas nos documentos e monumentos.

Cientes de que não exista harmonia natural na sociedade, compreendemos as diferentes sociedades humanas como historicamente determinadas em seus diferentes períodos por modos diversos de sobrevivência material e cultural, o que não implicará em análises mecanicistas e viciadas por determinações partidárias, pois apesar de os resultados das análises serem "desagradáveis" aos nossos olhos, não é revolucionário e científico manipular as fontes históricas para atender nossos objetivos políticos.

Esse artigo também constatou que a prática pedagógica também é enriquecida com esses estudos históricos de instituições escolares, pois os professores, alunos e funcionários podem se auxiliar dessas informações históricas para aprimorar sua prática educativa e melhor compreender a própria educação praticada em uma dada sociedade, pois por meio do conjunto das histórias das instituições escolares podemos entender o processo educativo escolar, ou seja, o estudo da história das escolas é a própria história da educação.

Por isso, não é possível entender a história se os estudos ficarem limitados aos acontecimentos internos da escola, pois a maior parte das relações internas de uma instituição escolar é reflexo de questões de nível local, nacional e até mesmo internacional. Devemos nos atentar as relações dialéticas das escolas com a sociedade, a política e 
sobretudo os meio materiais de produção (economia), ou seja, relacionar o singular com o geral.

Em suma, o fundamental do método não está na consideração abstrata dos dois termos, a escola separada da sociedade, relacionados a posteriori, mas na relação constitutiva e integral entre eles, pois esses termos só existem nessa relação, ou seja, a escola e a sociedade fazem parte de uma totalidade inserida em um determinando contexto histórico, econômico, cultural, político e ideológico.

A dialética não é uma relação mecânica ou abstrata que descortina, para além da aparência (escola), uma essência metafísica (sociedade). Ao contrário, é uma condição recíproca de existência. Assim, como uma determinada sociedade foi condição para a criação e o desenvolvimento de uma determinada instituição escolar, esta é a condição de existência daquela, porque lhe molda suas relações de produção.

Enfim, assim como no chão da escola como no campo de estudos e pesquisas da Educação na academia, a sociedade opera de forma conflituosa, pois suas opostas classes sociais lutam, em opostos campos, em favor de escolas e estudos científicos que atendam aos seus próprios interesses.

\section{REFERÊNCIAS}

ARAÚJO, J. C. S.; GATTI JUNIOR., D. (Org.). Novos temas em história da educação brasileira. Instituições escolares e educação na imprensa. Campinas, SP: Autores Associados; Uberlândia, MG: EDUFU, 2002.

BETTO, F. Batismo de sangue: guerrilha e morte de Carlos Marighella. Rio de Janeiro: Rocco, 2006.

BUFFA, E.; NOSELLA, P. Instituições escolares: porque e como pesquisar. Campinas, SP: Alínea, 2009.

BURKE, P. A escola dos Annales (1929-1989): a Revolução Francesa da historiografia. São Paulo: Ed. da UNESP, 1997.

CHAUÍ, M. Brasil: mito fundador e sociedade autoritária. São Paulo, SP: Fundação Perseu Abramo, 2000.

DOSSE, F. A história em migalhas: dos Annales à Nova História. Bauru, SP: EDUSC, 2003.

LE GOFF, J. História e memória. Campinas, SP: Ed. da UNICAMP, 1990.

GRAMSCI, A. Concepção dialética da história. Rio de Janeiro: 10. ed. Civilização Brasileira, 1995. 
Artigo

doi: $10.20396 /$ rho.v18i4.8652660

HALIMI, S. Dos miseráveis da terra à camada média superior: a armadilha dos $99 \%$.

Revista Le Monde Diplomatique Brasil, Edição de 20 de setembro de 2017. Disponível em: 〈http://diplomatique.org.br/a-armadilha-dos-99/>. Acesso em: 28 set. 2017.

HOBSBAWM, E. J. Sobre história. São Paulo: Companhia das Letras, 1999.

KUSHNIR, B. A grande imprensa apoiou o golpe e a ditadura. Revista Carta Capital, Especial 50 anos do golpe. Publicado em 31 mar. 2014. Disponível em:

$<$ http://www.cartacapital.com.br/politica/a-grande-impressa-apoiou-o-golpe-e-a-ditadurae-nao-teve-papel-relevante-para-o-fim-do-regime-1979.html>. Acesso em: 19 fev. 2016.

LOWY, M. As Aventuras de Karl Marx contra o Barão de Munchhausen: marxismo e positivismo na sociologia do conhecimento. São Paulo: Busca Vida, 1987.

LOWY, M. Ideologia e ciências sociais: elementos para uma análise marxista. 12. ed. São Paulo: Cortez, 1998.

MAGALHÃES, J. P. Tecendo nexos: história das instituições educativas. Bragança Paulista: EDUSF, 2004.

MAGALHÃES, J. P. Um apontamento metodológico sobre a história das instituições educativas. In: SOUSA, C. P. de.; CATANI, D. B. (Org.). Práticas educativas, culturas escolares, profissão docente. São Paulo: Escrituras, 1998.

MARTÍN, M. Polícia do Rio forja cena de crime para esconder assassinato de jovem. Jornal El país (Brasil). Rio de Janeiro, 30 nov. 2015. Disponível em: <http://brasil.elpais.com/brasil/2015/09/30/politica/1443571133_773507.html>. Acesso em: 19 fev. 2016.

MARX, K. Posfácio à Segunda Edição Alemã (1872) do Primeiro Volume de "O Capital”. Editorial"Avante!" Transcrição e HTML: Fernando A. S. Araújo, março 2007. Disponível em: <https://www.marxists.org/portugues/marx/1873/01/24.htm>. Acesso em: 21 jan. 2016.

MARX, K. O capital. Livro 1, v. II. 25. ed. Rio de Janeiro: Civilização Brasileira, 2011.

MARX, K.; ENGELS, F. A ideologia alemã. Trad. Bruni, José Carlos e Nogueira, Marco Aurélio. São Paulo: Hucitec, 1987.

MENDONÇA, S. R. de. As políticas de educação rural do Ministério da Agricultura (1945-1961). In: CONGRESSO BRASILEIRO DE HISTÓRIA DA EDUCAÇÃO, 5. 2008, Sergipe. Anais... Sergipe: SBHE, 2008. p. 1-14.

MOLINA, R. S. Escola agrícola prática "Luiz De Queiroz" (ESALQ/USP): sua gênese, projetos e primeiras experiências - 1881 a 1903. 2011. Dissertação (Mestrado) Universidade Estadual de Campinas, Campinas, 2011. 
Artigo

doi: $10.20396 /$ rho.v18i4.8652660

MOLINA, R. S. Ditadura, agricultura e educação: a USP/ESALQ e a "modernização conservadora" do campo brasileiro (1964 a 1985). 2016. Tese (Doutorado) - Universidade Estadual de Campinas, Campinas, 2016.

MORAES, D. de. O jornalista Antonio Gramsci. Revista Carta Maior [2013]. Mídia. Disponível em: <http://www.cartamaior.com.br/?/Editoria/Midia/O-jornalista-AntonioGramsci/12/29684>. Acesso em: 06 ago. 2015.

MINTO, L. W. A educação da miséria: particularidade capitalista e educação superior no Brasil. São Paulo: Outras Expressões, 2014.

NORONHA, O. M. Historiografia das instituições escolares: contribuição a debate metodológico. In: SAVIANI, D.; NASCIMENTO, M. S.; SANDANO, W.; LOMBARDI, J. C. (Org.). Instituições escolares no brasil: conceito e reconstrução histórica. Campinas, SP: Autores Associados: HISTEDBR, 2007, p. 165-173.

SANFELICE, J. L.; JACOMELI, M. R. M.; PENTEADO, A. E. A. P. (Org.). História de instituiçõos escolares. Bragança Paulista, SP: Margem da Palavra, 2016.

SANFELICE, J. L. História e historiográfica de instituições escolares. Revista

HISTEDBR On-line, Campinas, n. 35, p. 192-200, set. 2009. Disponível em:

<https://periodicos.sbu.unicamp.br/ojs/index.php/histedbr/article/view/8639622/7190>.

Acesso em: 19 out. 2018.

SANFELICE, J. L. História, instituições escolares e gestores educacionais.

Revista HISTEDBR On-line, Campinas, n. especial, p. 20-27, ago. 2006.

SAVIANI, D. et al. Instituições escolares no Brasil: conceito e reconstrução histórica. NASCIMENTO, M. S.; SANDANO, W.; LOMBARDI, J. C. (Org.). Campinas, SP: Autores Associados: HISTEDBR, 2007.

SAVIANI, D. Antecedentes, origem e desenvolvimento da pedagogia histórico-crítica. In: MARSIGLIA, A. C. G. (Org.). Pedagogia histórico - crítica: 30 anos. Campinas-SP: Autores Associados, 2011.

SCHAFF, A. História e verdade. São Paulo: Martins Fontes, 1987.

\section{Notas}

${ }^{1}$ Professor Adjunto da Universidade Federal do Maranhão (UFMA). Pós-doutor em Fundamentos da Educação pela PUC-Campinas. Realizou doutorado e mestrado em História e Filosofia da Educação na Universidade Estadual de Campinas (FE/UNICAMP). É graduado em História pela Universidade Metodista de Piracicaba (UNIMEP).

${ }^{2}$ Esse artigo é um dos resultados da tese de Doutorado (MOLINA, 2016) desenvolvida no Programa de PósGraduação em Educação da FE/UNICAMP, financiado pela Coordenação de Aperfeiçoamento de Pessoal de Nível Superior (CAPES) e Conselho Nacional de Desenvolvimento Científico e Tecnológico (CNPq). 
3 A própria ideia de que o país foi "descoberto" por portugueses guiados por Deus foi uma ideia ideologicamente construída, já que as terras que chamamos Brasil já eram habitadas por milhões de indígenas. (CHAUÍ, 2000).

${ }^{4}$ Em 1919, ao lado de Palmiro Togliatti, Umberto Terracini e Angelo Tasca, Gramsci fundou o semanário L'Ordine Nuovo, cujo subtítulo era "Resenha semanal de cultura socialista". Tendo Gramsci como editorchefe, L'Ordine Nuovo circulou de $1^{\circ}$ de maio de 1919 a 24 de dezembro de 1920. Em $1^{\circ}$ de janeiro de 1921 , o jornal passou a ser diário, sob o lema "Dizer a verdade é revolucionário". Vinte dias depois, passou a ser o órgão central do Partido Comunista Italiano (PCI), que acabara de ser fundado. Gramsci foi seu redator-chefe e articulista até 1924, quando L'Ordine Nuovo acabou substituído por L'Unità ("Diário dos operários e dos camponeses"). (MORAES, 2013).

${ }^{5}$ Esse fenômeno também ocorreu no regime burocrático-stalinista da ex-URSS quando a ciência política e econômia foram radicalmente instrumentalizadas e ideologizadas, abolindo qualquer autonomia relativa da história. Essa ideologização total também era presente nas ciências da natureza. "A ideia de que as ciências naturais existentes teriam um caráter burguês é estranha ao pensamento dos clássicos do marxismo; trata-se de uma inovação teórica do estalinismo, que se poderia designar positivismo ao inverso: enquanto o positivismo quer naturalizar as ciências sociais e políticas, o estalinismo pretende 'politizar' as ciências da natureza; os dois têm em comum a incompreensão da especificidade das ciências humanas e de sua distinção metodológica com relação às ciências naturais." (LOWY, 1987, p. 161).

${ }^{6}$ A História se confronta com 2 grandes problemas, a História "[...] solução para todos os problemas [...]" que mecanicamente, rígida e imutável resolve soluções por meio de modelos com resultados fascinantes. Outro ponto problemático é a História manipulada, distorcida sistematicamente com fins políticoeconômicos, especialmente dentro de escolas, fenômenos que desencadeiam orgulhos nacionalistas, xenofobia e outros problemas sociais. (HOBSBAWM, 1999, p. 28).

7 "Os meios de comunicação são empresas que buscam o lucro, vendendo a visão particular sobre um fato e, como Abramo por vezes demarcou, um "equívoco que a esquerda geralmente comete é o de que, no Brasil, o Estado desempenha papel de controlador maior das informações. Mas não é só o Estado, é uma conjunção de fatores. O Estado não é capaz de exercer o controle, e sim a classe dominante, os donos. O Estado influi pouco, porque é fraco. Até no caso da censura, ela é dos donos e não do Estado. Não é o governo que manda censurar um artigo, e sim o próprio dono do jornal. Como havia censura prévia durante o regime militar, para muitos jornalistas ingênuos ficou a impressão de que eles e o patrão tinham o mesmo interesse em combater a censura". (KUSHNIR, 2014).

${ }^{8}$ Mesmo com o fim da ditadura, o Estado brasileiro continua forjando crimes. (MARTín, 2015).

${ }^{9}$ Uma história da educação positivista preocupa-se mais com certos temas, aqueles exatamente em que é possível encontrar documentos escritos que falem por si mesmos, dispensando a interferência ativa do historiador. São exemplos destes temas, a história da legislação escolar, a do pensamento educacional de um educador considerado relevante, que, sem dúvida, marcaram os inícios da pesquisa em história da educação brasileira. (BUFFA; NOSELLA, 2009, p. 60).

Submetido em: 06/06/2018

Aprovado em: 22/09/2018

Publicado em: 18/12/2018 